\title{
Universiteit
}

Leiden

The Netherlands

\section{C MAS NMR evidence for a homogeneously ordered environment of tyrosine M210 in reaction centres of Rhodobacter sphaeroides}

Shochat, S.; Gast, P.; Hoff, A.J.; Boender, G.J.; Leeuwen, S. van; Liemt, W.B.S. van; ... ; Groot, H.J.M. de

\section{Citation}

Shochat, S., Gast, P., Hoff, A. J., Boender, G. J., Leeuwen, S. van, Liemt, W. B. S. van, ... Groot, H. J. M. de. (1995). 13C MAS NMR evidence for a homogeneously ordered environment of tyrosine M210 in reaction centres of Rhodobacter sphaeroides.

Spectrochimica Acta Part A : Molecular And Biomolecular Spectroscopy, 51(1), 135-144. doi:10.1016/0584-8539(94)00207-R

Version: $\quad$ Publisher's Version

License: $\quad$ Licensed under Article 25fa Copyright Act/Law (Amendment Taverne)

Downloaded from: $\quad$ https://hdl.handle.net/1887/3239395

Note: To cite this publication please use the final published version (if applicable). 


\title{
${ }^{13} \mathrm{C}$ MAS NMR evidence for a homogeneously ordered environment of tyrosine M210 in reaction centres of Rhodobacter sphaeroides
}

\author{
S. Shochat, P. Gast and A. J. Hoff \\ Biophysics Department, Huygens Laboratory, Leiden University, P.O. Box 9504, 2300 RA Leiden,
} The Netherlands

and

\author{
G. J. Boender, S. van Leeumen, W. B. S. van Liemt, E. Vijgenboom, J. Raap, \\ J. Lugtenburg and H. J. M. De Groot \\ Leiden Institute of Chemistry, Gorlaeus Laboratories, Leiden University, P.O. Box 9502, 2300 RA Leiden, \\ The Netherlands
}

(Received 2 September 1994)

\begin{abstract}
The initial electron transfer time in the photosynthetic reaction centre of Rhodobacter sphaeroides is highly sensitive to the replacement of tyrosine M210 by a tryptophan residue. Low-temperature magic angle spinning ${ }^{13} \mathrm{C}$ NMR is used to study Rhodobacter sphaeroides 2.4.1 (M)Y210W mutant reaction centres that are labelled with $\left[4^{\prime}{ }^{13} \mathrm{C}\right]$ tyrosine. The response of $(\mathrm{M}) \mathrm{Y} 210$ in $\mathrm{R} 26$ is assigned unambiguously to the most upfield narrow signal (linewidth $34 \mathrm{~Hz}$ ) at $\sigma_{\mathrm{i}}=152.2 \mathrm{ppm}$, in the region where non-hydrogen bonded tyrosine signals are expected. From the comparison with the signal of labelled R26 it follows that the chemical environment of the (M)Y210 label is unique. The Y(M)210 is in a structurally and electrostatically homogeneous region on the sensitivity scale of the MAS NMR technique. The environment of M210 is structurally stable and the observation of a narrow line shows that the (M)Y210 side chain can be considered static with respect to rotational diffusion on time scales as long as $10^{-2} \mathrm{~s}$. The narrow signals from the remaining labels in the protein interior for the 2.4.1 (M) Y210W mutant are remarkably similar to those observed for R26. Using a commonly accepted ratio of $150 \mathrm{ppm}$ shift per positive charge equivalent for aromatic carbons, the chemical shift differences between mutant and R26 translate into small variations of the order of $10^{-3}$ electronic equivalents of charge polarization. Also the linewidths are similar, except for a narrow response at $\sigma_{i}=156.4 \mathrm{ppm}$ that sharpens slightly in the (M)Y210W mutant. Thus, the influence of the (M)Y210W mutation on the global electrostatic properties and structure of the protein, as probed by the tyrosine labels, is minimal. This strongly argues against an explanation of slow and non-exponential electron transfer kinetics in the (M)Y210W RC in terms of loss of structural integrity upon mutation. In contrast, the NMR results strongly support current opinions that (M) Y210 contributes to the fine-tuning of the energy levels of prosthetic groups involved in electron transfer.
\end{abstract}

\section{INTRODUCTION}

Photochemical energy conversion in bacterial photosynthesis takes place in the photosynthetic reaction centre (RC). This transmembrane protein complex comprises three polypeptide subunits $(\mathrm{L}, \mathrm{M}$ and $\mathrm{H})$ that support the bacteriochlorophyll $\left(P, B_{A}, B_{B}\right)$, bacteriopheophytin $\left(\Phi_{A}, \Phi_{B}\right)$ and quinone $\left(Q_{A}, Q_{B}\right)$ cofactors (cf. Fig. 1). The cofactors form two nearly symmetric branches designated $A$ and $B$ [1-3]. The photochemistry involves the transfer of electrons from a bacteriochlorophyll dimer $(\mathrm{P})$ at the periplasmic side of the RC through the A-branch via bacteriopheophytin $\Phi_{\mathrm{A}}$ and possibly monomeric bacteriochlorophyll to the primary quinone $Q_{A}$.

One of the central questions in photosynthesis research is, how do the polypeptide chains that provide the RC with its specific geometry and support the cofactors, contribute to the functional symmetry breaking between the A- and the B-branch, and influence the mechanism of electron transport. The primary photochemistry in the bacterial RC is at least bi-exponential. This non-exponentiality of electron transfer has been attributed, among other possibilities, to structural or electrostatic sample inhomogeneities [4-7].

With the aim of gaining more insight into both structural and electrostatic heterogeneities of the protein matrix and its dynamic properties, cross polarization (CP) magic angle spinning (MAS) NMR was used previously to study $\left[4^{\prime}-{ }^{13} \mathrm{C}\right]$ tyrosine-enriched samples of 


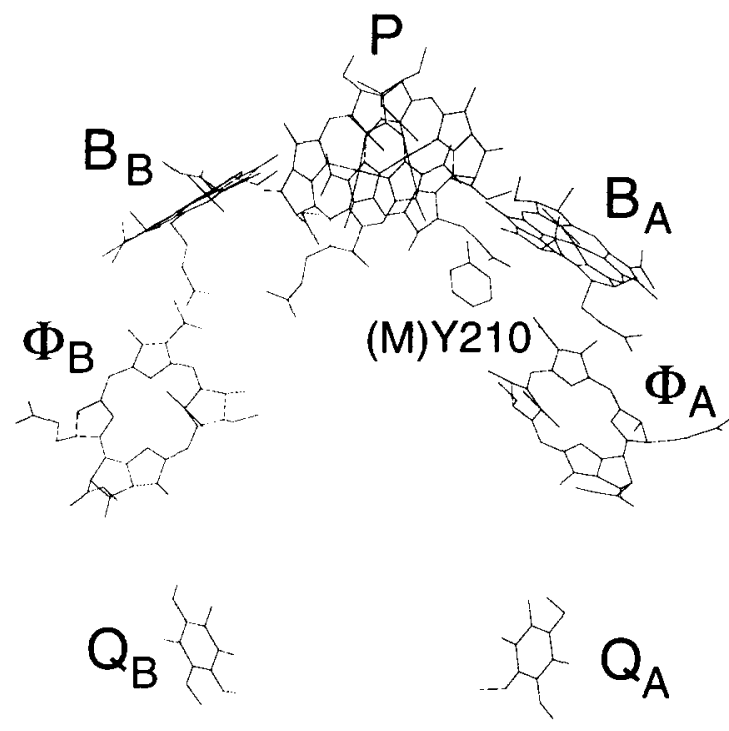

Fig. 1. Arrangement of the side chain of (M)Y210 with respect to the cofactors in the Rhodobacter sphaeroides RC $[2,3]$. For optimal clarity the phytyl and isoprenic chains of the cofactors are not shown.

RCs from Rhodobacter sphaeroides R-26 in the dark and after illumination $[8,9]$. However, the R-26 RC comprises a total of 28 tyrosines distributed over the complex and therefore only a global characterization of the vicinity of the special pair could be obtained, suggesting that on the scale of the MAS NMR at least part of the protein environment of the special pair is surprisingly ordered.

In this work we report on the ${ }^{13} \mathrm{C}$ MAS NMR of $\left[4^{\prime}-{ }^{13} \mathrm{C}\right]$ Tyr labelled RC with the Tyr M210 changed into a tryptophan. The purpose of this study is twofold. First, it was inferred that the highly conserved (M)Y210, which is of importance for the efficiency of electron transfer, is in a strictly unique, well-ordered and stable hydrophobic part of the RC interior [9]. However, this could only be based on a preliminary and tentative assignment of its NMR signal. A definite assignment of the (M) Y210 signal is now obtained by collecting CP/MAS NMR difference data of RCs of labelled (M)Y210W mutant and by comparing these data with a difference spectrum of labelled R-26 RC. It is shown here unambiguously that it is indeed the protein environment of M210 which is structurally and electrostatically (and in this sense functionally) homogeneous on the scale of the NMR. Second, the functional characterization of the (M)Y210W mutant revealed strongly non-exponential electron transfer kinetics, raising the question whether this mutation induces pronounced heterogeneity in the RC complex [10-12]. Therefore, effects of the mutation on the global structural and electrostatic integrity of the $\mathrm{RC}$ are characterized through a detailed analysis of the ${ }^{13} \mathrm{C}$ MAS NMR response of the $\left[4{ }^{\prime}-{ }^{13} \mathrm{C}\right] \mathrm{Tyr}(\mathrm{M}) \mathrm{Y} 210 \mathrm{~W}$ species.

\section{EXPERIMENTAL}

High-resolution solid state NMR is an excellent technique for the characterization of large membrane protein complexes with atomic selectivity when used in conjunction with site-directed isotope enrichment for enhancement of the NMR response and site-specific mutagenesis for the assignment of the signals from particular amino acids.

Highly enriched $(99 \%)\left[4-{ }^{13} \mathrm{C}\right] \mathrm{L}$-tyrosine was synthesized from $\left[2-{ }^{13} \mathrm{C}\right]$ acetone in a six-step procedure (Scheme 1). First, the labelled acetone was converted into methyl-3- ${ }^{13} \mathrm{C}$ acetoacetate using potassium hydride and dimethyl carbonate. Following the procedure described in Ref. [13], the labelled methyl acetoacetate was then condensed with nitromalonaldehyde to give methyl $\left[2-{ }^{13} \mathrm{C}\right] 5$-nitrosalicate, which was then reduced to the corresponding 5-aminosalicate using $\mathrm{NaBH}_{4}$, and $\mathrm{Pd} / \mathrm{C}$ as a catalyst. Subsequent treatment with $\mathrm{NaNO}_{2} / \mathrm{HCl}$, followed by reaction with $\mathrm{H}_{3} \mathrm{PO}_{2}$ 
$\mathrm{KH}, 18$ crown-6
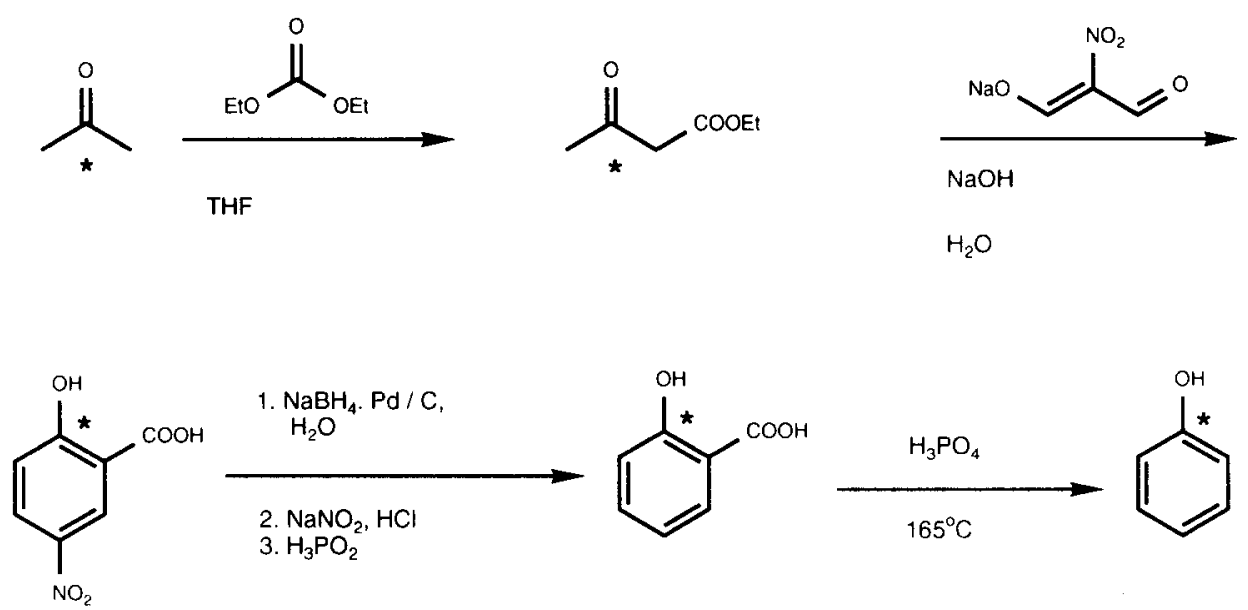

Scheme 1 .

gave methyl $\left[2-{ }^{13} \mathrm{C}\right]$ salycate, which was decarboxylated using concentrated phosphoric acid at $165^{\circ} \mathrm{C}$. The resulting $\left[1-{ }^{13} \mathrm{C}\right]$ phenol was converted into $\left[4-{ }^{13} \mathrm{C}\right] \mathrm{L}-$ tyrosine as described in Ref. [13]. This newly developed reaction sequence is convenient with respect to work-up procedures and gives an overall yield of $48 \%$.

Cells of the deletion mutant of Rhodobacter sphaeroides 2.4.1, complemented with plasmid bearing wild-type genes or the mutation (M)Y210W, were grown on a synthetic medium containing the labelled tyrosines [14]. The RCs were isolated as described in Ref. [11]. Approximately $15 \mathrm{mg}$ of the RC protein complex embedded in $N, N$-dimethyldodecylamine- $N$ oxide (LDAO) micelles was obtained. The sample purity was determined by measuring the $\mathrm{A}_{280} / \mathrm{A}_{802}$ ratio for the wild type and the $\mathrm{A}_{280} / \mathrm{A}_{806}$ ratio for the mutant. These ratios were between 1.2 and 1.4. By monitoring the kinetics of the reversible photobleaching at $865 \mathrm{~nm}$ on a millisecond time scale it was found that for the mutant RCs at least $90 \%$ of the $Q_{A}$ sites and $60 \%$ of the $Q_{B}$ sites were occupied after the isolation procedure. In the wild type $R C s$ virtually all $Q_{A}$ and $Q_{B}$ were still present. The $\left[4^{\prime}-{ }^{13} \mathrm{C}\right] \mathrm{Tyr}$ incorporation in the complex was determined by mass spectrometry and was $>95 \%[14]$.

Low-temperature $100 \mathrm{MHz}{ }^{13} \mathrm{C} \mathrm{CP} / \mathrm{MAS} \mathrm{NMR}$ experiments were performed with a MSL400 NMR spectrometer using a $7 \mathrm{~mm}$ MAS probe (Bruker, Karlsruhe, Germany). The spinning rate at the magic angle was kept constant with a home built spinning speed controller [15]. Spectra were accumulated in up to $8 \mathrm{~K}$ channels with ${ }^{1} \mathrm{H}$ decoupling during acquisition. The $90^{\circ}$ pulse lengths for the ${ }^{1} \mathrm{H}$ and ${ }^{13} \mathrm{C}$ were $8 \mu \mathrm{s}$; the mixing time was $1 \mathrm{~ms}$, the recycle delay $2 \mathrm{~s}$ and the sweep width $50 \mathrm{kHz}$.

The tyrosine signals were separated from the natural abundance background by subtracting a spectrum obtained at the same spinning speed from a natural abundance sample at the same temperature, using procedures described in Ref. [15]. Centrebands of difference spectra were deconvoluted with Lorentzian lines using the Speedyfit computer programme on a Silicon Graphics 4D35 workstation [16].

In order to immobilize the detergent-solubilized protein complex, the samples were frozen using liquid nitrogen cooled bearing gas [17]. The temperature $T_{\mathrm{B}}$ of the gas is measured just before entering the stator. The actual sample temperature is higher and depends slightly on the amount of drive gas, which was kept at ambient temperature. A reasonable estimate for the sample temperature $T$, accurate to about $5 \mathrm{~K}$, can be obtained using $T \sim 0.86 T_{\mathrm{B}}+50 \mathrm{~K}$.

The spectra are referenced relative to tetramethylsilane (TMS), using the signal at $14.4 \mathrm{ppm}$ from the ${ }^{13} \mathrm{C}-12$ of the LDAO as an internal calibration. All CP/MAS data were taken with the same dead time of $10 \mu \mathrm{s}$, and the first-order phase correction after Fourier transformation was kept at $25^{\circ}$. With this procedure the absolute error in the chemical shift is $\sim 0.2 \mathrm{ppm}$ [9].

\section{Results AND Discussion}

There are several polar amino acids in the vicinity of the special pair that break the symmetry of the RC. One particular tyrosine, (M) Y210, which is highly conserved 


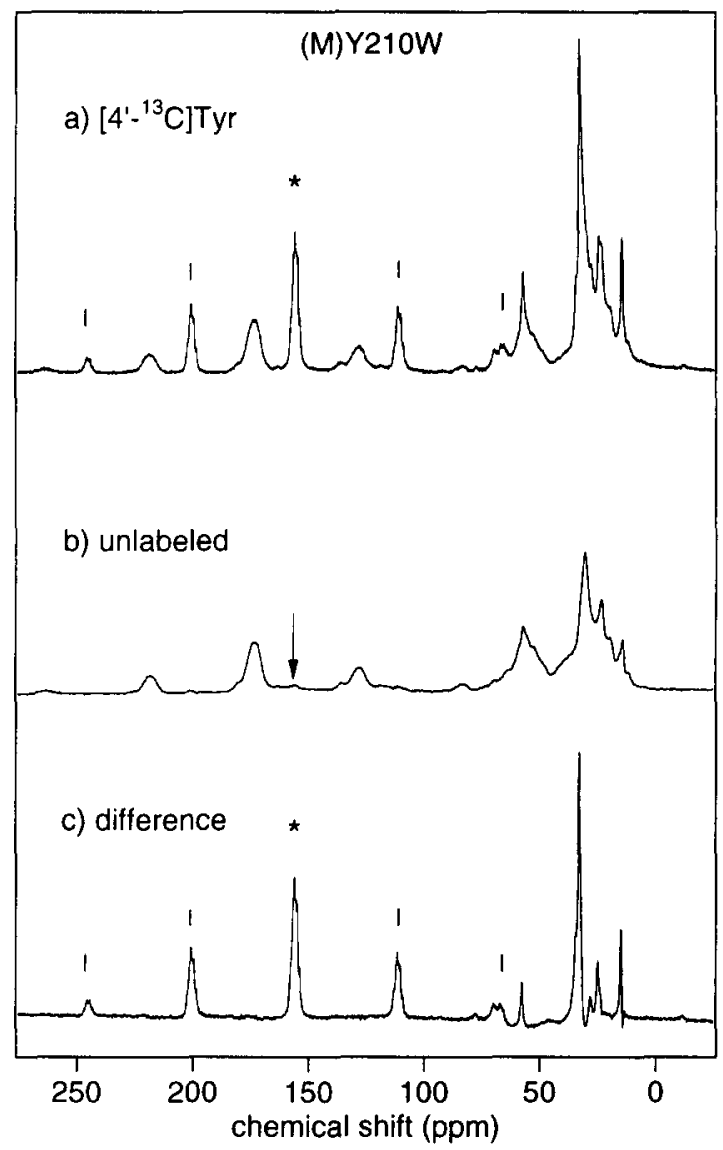

Fig. 2. CP/MAS difference spectroscopy for the labelled Rhodobacter sphaeroides (M)Y210W mutant. (a) Proton-decoupled ${ }^{13} \mathrm{C} \mathrm{CP/MAS} \mathrm{NMR} \mathrm{spectrum} \mathrm{for}\left[4^{\prime}-{ }^{13} \mathrm{C}\right] \mathrm{Tyr}$ (M)Y210W RC. (b) Spectrum of an unlabelled (M) Y210W RC sample and (c) difference spectrum (a) minus (b). Data were taken at $T=230 \mathrm{~K}$ with $\omega_{\mathrm{r}} / 2 \pi=4.50 \mathrm{kHz}$. The centreband and sidebands from the label are indicated with $\left(^{*}\right)$ and $(\mid)$, respectively. The arrow indicates a weak natural abundance signal at almost the same position as the centreband from the label.

between different species, is of importance for the efficiency of electron transfer, but the precise molecular mechanism by which it operates is as yet unclear. It has been suggested from electrostatic calculations that the presence of (M) Y210 lowers the energy of $\mathrm{P}^{+} \mathrm{B}_{\mathrm{A}}^{-}$, which affects the mechanism of electron transfer through the A-branch [18]. Indeed it was found that the electron transfer kinetics from $P$ to $\Phi_{A}$ and the redox potential of $P$ are altered when this tyrosine, close to $P, B_{A}$ and $\Phi_{A}$, is substituted by other amino acids [10-12, 19-22].

To characterize the chemical environment of (M)Y210 with NMR a $\left[4^{\prime}-{ }^{13} \mathrm{C}\right]$ Tyr $\mathrm{Y}(\mathrm{M}) 210$ mutant was prepared for the assignment of its ${ }^{13} \mathrm{C}$ label resonance. Figure 2(a) shows CP/MAS NMR response of the mutant, recorded with a spinning speed $\omega_{\mathrm{T}} / 2 \pi=$ $4.50 \mathrm{kHz}$ at $T=230 \mathrm{~K}$ from frozen RC solutions. The strong signals around 200,155 , and $110 \mathrm{ppm}$ are associated with the isotope labels [9]. The natural abundance ${ }^{13} \mathrm{C}$ background signals of the aliphatic carbons are found between 0 and $75 \mathrm{ppm}$, while the peptide carbonyl background signal is centred at $\sim 175 \mathrm{ppm}$ with sidebands at 130 and $220 \mathrm{ppm}$. Between 120 and $140 \mathrm{ppm}$ also the centrebands of the aromatic and olefinic backgrounds are weakly visible.

A natural abundance spectrum was collected at the same spinning speed for an unlabelled (M)Y210W RC sample (Fig. 2(b)). These natural abundance data are the same as found for natural abundance R-26. The spectrum of Fig. 2(b) was subtracted from the data in Fig. 2(a), and the resulting difference spectrum is shown in Fig. 2(c). The main reason for performing the more accurate difference spectroscopy is the 


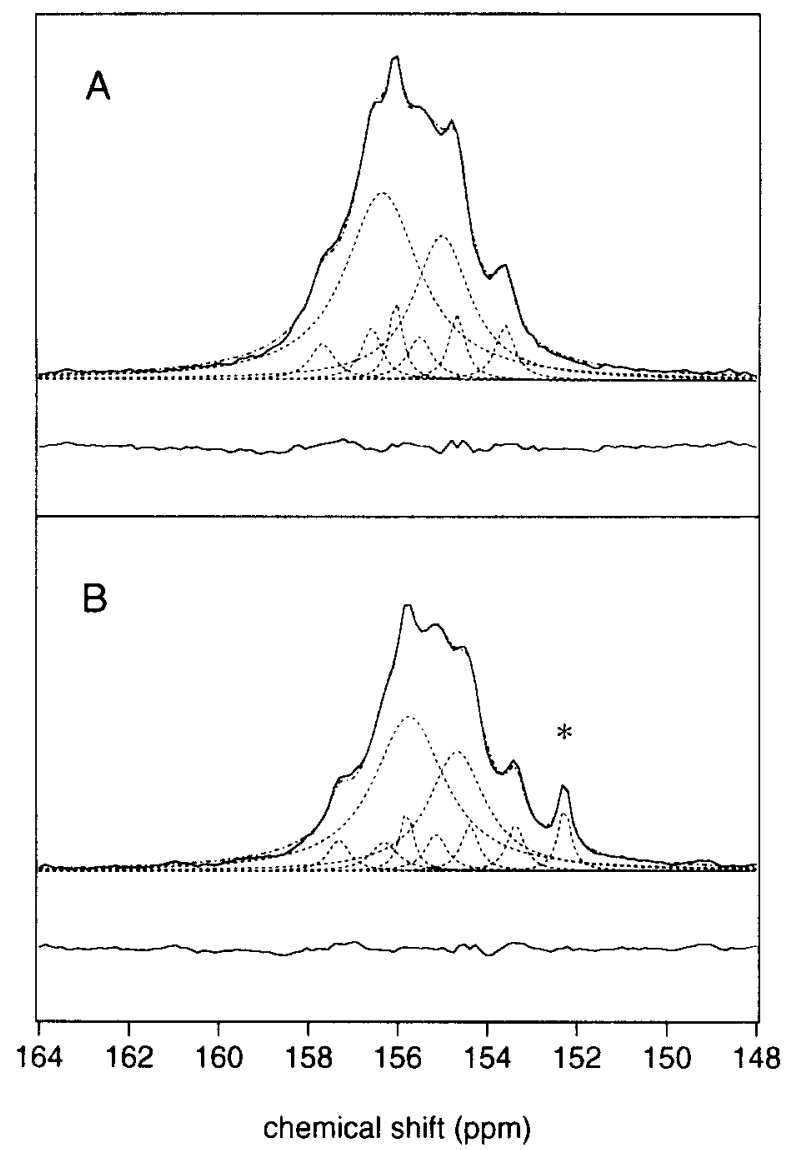

Fig. 3. (A) Deconvolution of the centreband in the (M)Y210W difference spectrum from Fig. 2(c), compared with (B) the deconvolution of the centreband of the label in $\left[4^{\prime}-{ }^{13} \mathrm{C}\right] \mathrm{Tyr} \mathrm{R}-26 \mathrm{RC}$. Data are represented by solid lines, the fits by dot-dashed lines, while the individual components that contribute to each fit are dashed. Below each band the residue, data minus fit, is shown.

presence of a weak natural abundance signal around $156 \mathrm{ppm}$, indicated by the arrow in Fig. 2(b). This partly arises from other moieties of the complex, for instance natural abundance arginine signals. In order to achieve the best possible signal to noise ratio for the difference spectrum a very concentrated unlabelled (M)Y210W sample was used to obtain the data in Fig. 2(b). Since the two sample preparations are not exactly the same, natural abundance difference signals, mainly from the LDAO detergent, are observed in the aliphatic region, but not in the centreband region of the tyrosine labels around $155 \mathrm{ppm}$.

The $\left[4^{\prime}-{ }^{13} \mathrm{C}\right] \mathrm{Tyr}$ centreband of the difference spectrum for the mutant in Fig. 2(c) is shown in Fig. 3(A), and compared with the data for R-26 from Ref. [9] in Fig. 3(B). Both signals contain a variety of narrow peaks and shoulders that correspond to the responses from individual tyrosines in the protein interior. These signals are better visualized by taking the second derivatives of the data (Fig. 4). From the comparison with the (M) Y210W data in Figs 3 and 4 the signal from (M)Y210 can now be assigned unambiguously. It is obvious that the entire signal at $152.2 \mathrm{ppm}$ (indicated by an asterisk) in R-26 is associated with (M)Y210. The observation that only one narrow MAS NMR signal is suppressed in Figs 3(A) and 4(A) shows unambiguously that the direct environment of M210 label is unique. MATtioli et al. reported that $\mathrm{Y}(\mathrm{M}) 210$ is probably not hydrogen bonded [23]. This is expected to produce a $\left[4-{ }^{13} \mathrm{C}\right]$ resonance frequency several ppm upfield from the hydrogen bonded side chains, in agreement with the NMR experiments [9].

The signal at $152.2 \mathrm{ppm}$ in Fig. 3(B) is completely suppressed by the mutation. SHOCHAT et al. and VAN NOORT et al. (1994) found strongly non-exponential electron 


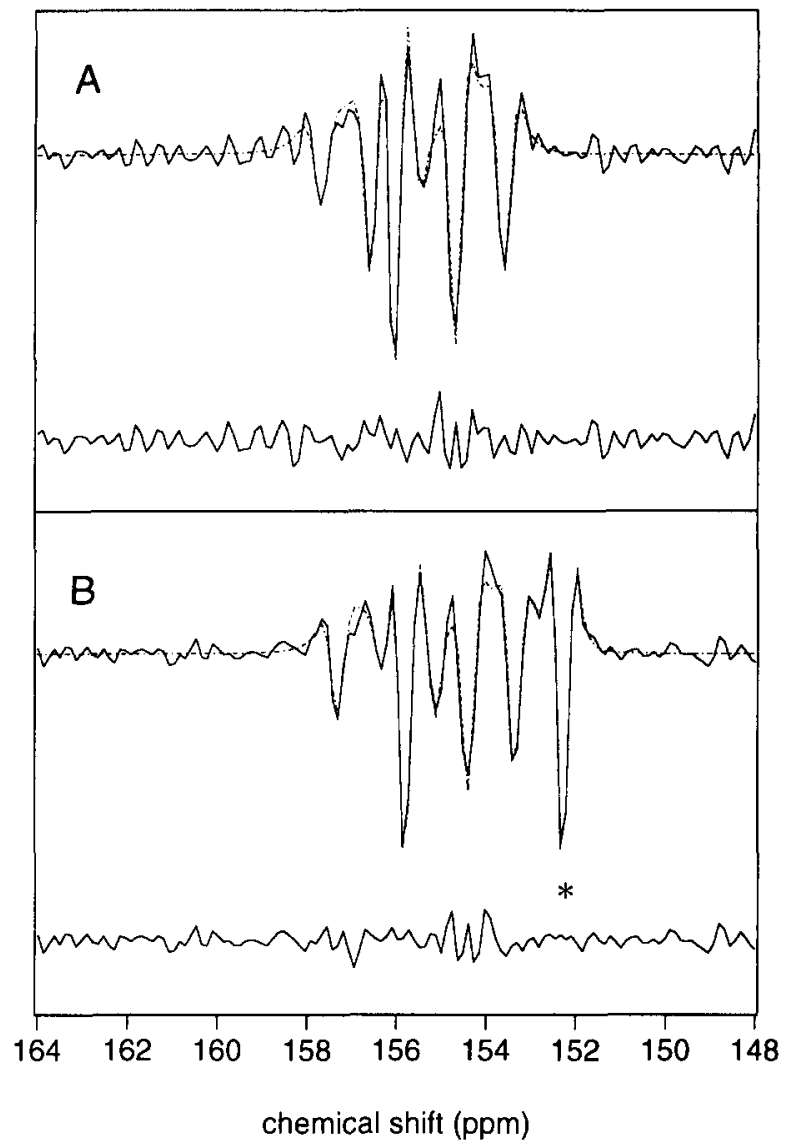

Fig. 4. Second derivatives of the data (solid lines) and the fits (dot-dashed lines) of the centreband signals in Fig. 3. Below each band the residue, data minus fit, is shown.

transfer kinetics with time constants of 5.1 and $36 \mathrm{ps}$ in an amplitude ratio $1: 3$ using $877 \mathrm{~nm}$ excitation in the same (M)Y210W mutant sample as used for the NMR $[11,12]$, while NAGARAJAN $e t$ al. reported a single time constant of 33 ps for the charge separation reaction in their preparation of the same species using $605 \mathrm{~nm}$ excitation [21]. The NMR data effectively exclude that a $>25 \%$ fast electron transfer component for our sample could be due to partial back-mutation.

Normally, ${ }^{13} \mathrm{C}$ resonances of proteins, including membrane proteins, are subject to some observable inhomogeneous broadening under MAS conditions when the temperature is lowered. Slight linebroadening has been observed for retinylidene label signals in the polar interior of the trans-membrane proton pump bacteriorhodopsin [24], while considerable broadening was reported for narrow components of tyrosine signals in the same protein when the temperature is lowered [25]. All narrow components in R-26 are subject to such additional broadening when the temperature is lowered except the two signals at 152.2 and $155.7 \mathrm{ppm}$ [9]. It was argued that they originate from tyrosines in a remarkably stable and nearly crystalline protein environment. The linewidth at lower temperatures remains $\sim 30 \mathrm{~Hz}$, which is very small and similar to what is obtained for quaternary carbons in a crystalline environment under CP/MAS conditions. Therefore, the linewidth is essentially limited by the intrinsic resolution of the ${ }^{13} \mathrm{C} C \mathrm{CP} / \mathrm{MAS}$ experiment.

The narrow signal at $152.2 \mathrm{ppm}$ is assigned to (M)Y210 by the mutation, and therefore this tyrosine is indeed located in an extremely well defined, unique, electrostatically homogeneous, and rigid environment. The observation of a line $34 \mathrm{~Hz}$ wide for (M)Y210 shows that its side chain can be considered static with respect to rotational diffusion on time scales as long as $10^{-2} \mathrm{~s}$. This is in agreement with the inferences made in the previous work [9]. Since the $152.2 \mathrm{ppm}$ resonance is the only signal that is suppressed by 
the mutation, our data provide strong evidence against structural or electrostatic (functional) heterogeneity in the chemical environment of M210 in the wild type, a possibility that has been suggested to explain the non-exponentiality of the primary charge transfer $[4,7]$. In this respect we note that the earlier NMR findings are now also perfectly matched by recent analyses of holeburning data indicating that the heterogeneity associated with a distribution of electronic coupling strengths or variations of the protein structure is not sufficient to explain the non-exponential decay of P870* $[26,27]$.

The effects on the electron transfer kinetics of mutations around $\mathbf{P}$, and in particular those of (M)Y210, are difficult to interpret and have been discussed in terms of a wide variety of possible mechanisms (see, e.g. Ref. [7]). A mutation inevitably alters the structure to some extent, which may lead to unpredictable results. For instance, (M)Y210 mutations may affect the free energy changes associated with the virtual and kinetic intermediates in the primary photochemical events [18,21]. Alternatively, the vibrational relaxation rate of $\mathrm{P}^{*}$ could be changed and conformational changes of prosthetic groups or the protein environment coupled to the primary transfer could be different. Finally, factors influencing the charge-separation kinetics like structural or functional sample heterogeneities or intrinsic properties of the primary events, for instance the introduction of additional intermediates or "parking states", have been proposed as possible factors that may be influenced by the mutation $[4,12]$.

For the Rhodobacter sphaeroides RC the changes in electron transfer kinetics upon M210 mutation are most spectacular when the tyrosine is replaced by a tryptophan. The primary charge separation rate is slowed down by more than a factor of 10 and is the slowest of all analogous mutants reported to date $[10,11,21]$. In addition, the redox potential of $P$ is increased by $52 \mathrm{mV}$ to $552 \mathrm{mV}$ compared to the wild type [21]. This could be related to unanticipated structural changes or increased heterogeneity associated with the mutation. To quantify the effect of structural changes associated with the mutation on the NMR response, the data in Figs 3 and 4 were deconvoluted. The results of these fits are summarized in Table 1. It appears that the remaining part of the $\left[4^{\prime}-{ }^{13} \mathrm{C}\right]$ Tyr signals in the carotenoid-less R-26 is almost identical in the (M) Y210W species which contains the carotenoid spheroidenone, since the cells were grown in the dark. A subtle difference is the linewidth of the signal at $156.2 \mathrm{ppm}$, which is smaller in the mutant. The differences in chemical shift for the individual components vary less than $0.4 \mathrm{ppm}$ between R-26 and (M)Y210W mutant (cf. Table 1). Since $160 \mathrm{ppm}$ corresponds to 1 unit of charge [28], this translates into variations of electrostatic polarization on individual residues in the order of $10^{-3}$ electronic equivalents. This is

Table 1. Deconvolution of the $\left[4-{ }^{13} \mathrm{C}\right]$ tyrosine centreband signal in the CP/MAS spectra of the labelled wild type and (M)Y210W RC. Isotropic chemical shifts $\sigma_{\mathrm{i}}$ and linewidths (FWHM) of the two strong broad components $(a, b)$ and the various small narrow resonances (i-vi) and the response of (M)Y210 in the wild type, are listed ${ }^{a}$

\begin{tabular}{ccccc}
\hline \multicolumn{3}{c}{ Wild type } & \multicolumn{3}{c}{$(\mathrm{M})$ Y210W } & \\
$\sigma_{\mathrm{i}}(\mathrm{ppm})$ & FWHM (Hz) & $\sigma_{\mathrm{i}}(\mathrm{ppm})$ & FWHM (Hz) & Component \\
\hline 154.6 & 154 & 155.0 & 152 & $\mathrm{a}$ \\
155.7 & 192 & 156.3 & 202 & b \\
157.2 & 57 & 157.6 & 67 & $\mathrm{i}$ \\
156.2 & 75 & 156.5 & 55 & ii \\
155.7 & 37 & 156.0 & 36 & iii \\
155.1 & 58 & 155.4 & 66 & iv \\
154.3 & 46 & 154.6 & 43 & v \\
153.3 & 46 & 153.5 & 52 & vi \\
152.2 & 34 & - & - & (M)Y210 \\
\hline
\end{tabular}

${ }^{a}$ Isotropic chemical shifts $\left(\sigma_{\mathrm{i}}\right)$ are in ppm relative to external TMS. The accuracies of the $\sigma_{\mathrm{i}}$ are determined by the digital resolution, which is $0.6 \mathrm{ppm}$. The measured linewidths are accurate to $\sim 10 \mathrm{~Hz}$ and the free induction decays were treated with $12 \mathrm{~Hz}$ exponential apodization prior to Fourier transformation and deconvolution analysis. 
very small, considering that the $4^{\prime}$-position in the phenolic side chain of the tyrosine provides a sensitive probe for variations in the chemical environment. Examples are differences in the hydrogen bonding environment, ring current effects, polarization by nearby polar residues or differences in conformation [9]. Using the label signals as internal markers, we conclude that all the observable tyrosines remain protonated and neutral. There is very little effect of both the mutation and the presence of the carotenoid on the overall structure and electrostatic properties of the frozen protein complex.

The present results correlate well with recent EPR and absorbance-detected magnetic resonance data that showed that the dimeric structure of $\mathbf{P}$ is not significantly changed upon the (M)Y210W mutation [11]. However, the $\mathrm{P}^{+} \mathrm{Q}_{\mathrm{A}}^{-}$back reaction in (M)Y210W is faster than in the wild type $[10,21]$, suggesting the possible occurrence of unpredictable global structural changes upon (M)Y210W mutation, while from LD-ADMR results it was found that the interaction of the accessory bacteriochlorophyll $B_{A}$ with its environment was slightly altered by the mutation [11]. This was tentatively interpreted in terms of a change of the orientation of $B_{A}$. The CP/MAS data for (M)Y210W provide strong evidence that such changes of the structure of the protein complex should be relatively small and local.

The similarity between the spectra for R-26 and (M)Y210W mutant is remarkable, considering that the mutation involves the replacement of the phenolic side chain of a tyrosine by a much bulkier indolic sidechain of a tryptophan that has to be accommodated by the structure. However, tryptophan has similar solvation and chemical character as tyrosine, frequently allowing mutual exchange without considerably affecting biological properties [29]. To further address this point, we have taken the X-ray structural data from ReEs et al. [2] and replaced the (M)Y210 by a tryptophan. The result was minimized with respect to the energy using the Biograf molecular modelling package. After minimization the indole side chain appeared to be partially forced out of the (M)Y210 pocket, penetrating into a region normally occupied by the detergent belt. This could possibly explain why this rather drastic mutation leaves the structure of the complex almost unaffected.

\section{Concluding Remarks}

MAS NMR in conjunction with site-directed isotope enrichment is at present the only technique that provides clear access to such important characteristics of the protein as local structural and electrostatic disorder, electrostatic polarizations of specific side chains and dynamics of the protein interior. The assignment of the $\left[4^{\prime}-{ }^{13} \mathrm{C}\right](\mathrm{M}) \mathrm{Y} 210$ signal proves that the immediate environment of (M)Y210 is unique and strongly resembles a crystalline solid on the scale of the CP/MAS NMR, in agreement with inferences made by FISCHER et al. [9]. As was pointed out previously [9], an elastic protein surrounding of the special pair could be of functional importance since it allows a precise positioning of the two chlorophylls in the special pair, yielding, for instance, the possibility for resonant superexchange processes to speed up electron transfer [30]. In addition it is definitely instrumental in preventing vibrational dephasing and relaxation, which may be of importance for the mechanism of charge separation [31].

Since a rigid structure means a small reorganization energy $\lambda$, it is not surprising that increasing experimental evidence is obtained that the "apparent" reorganization energy, in terms of the Marcus theory of electron transfer, is found to be rather small in different RC. Although the apparent $\lambda=12 \mathrm{meV}$ reported by DiMAGNo et al. [7] for Rhodobacter capsulatus may have been underestimated due to the presence of resonant superexchange [30], it correlates with the total $\lambda=45 \mathrm{meV}$ deducted by KolaczKowsKi et al. [26]. These values are small compared to the $\sim 250 \mathrm{meV}$ expected for classical electron transfer theory (see, e.g. Parson [32]). The type of rigid protein environment that transpires through the NMR analysis of the (M)Y210 signal appears to leave only very little room for structural changes associated with the photochemistry. 
The NMR data support models for changes in the kinetics and free energy gaps in the mutant with respect to the wild type that rely on local electrostatic effects related to the presence of (M)Y210, as opposed to pronounced structural changes associated with the mutation. Since the overall protein conformation of the (M)Y210W appears frozen in a highly similar state as in R-26, it is difficult to imagine that the temperature dependence of the primary charge separation rate, which is particularly strong for the (M)Y210W mutant $[12,21]$, is associated with temperature-dependent heterogeneity. In contrast, our NMR results support current ideas that electrostatic interactions between (M)Y210 and $B_{A}$ stabilize the state $P^{+} B_{A}^{-}[18]$. This would be altered upon substitution by the less polar tryptophan, explaining the different electron transfer kinetics in the (M)Y210W mutant, for instance by promoting temporary storage of the excitation in an "unrelaxed" $\mathrm{P}^{*}$ state or a charge-transfer "parking state" [4-12,21].

Acknowledgements-We thank A. H. M. de Wit and S. J. Jansen for culturing the cells and isolating the reaction centres. This research was supported by the Netherlands Foundations for Biophysical and Chemical Research, financed by The Netherlands Organization for Scientific Research (NWO), and by Twinning Grant No. SC 1-CT90-0569 of the European Community. PG and HJMdG are recipients of a research career development fellowship (Akademie-Onderzoekers) from the "Koninklijke Nederlandse Akademie van Wetenschappen" (Royal Dutch Academy of Sciences).

\section{REFERENCES}

[1] J. Deisenhofer and H. Michel, EMBO J. 8, 2149 (1989).

[2] D. C. Rees, H. Komiya, T. O. Yeates, J. P. Allen and G. Feher, Ann. Rev. Biochem. 58, 607 (1989).

[3] C. H. Chang, O. El Kabbani, D. Tiede, J. Norris and M. Schiffer, Biochemistry 30, 5352 (1991).

[4] P. Hamm, K. A. Gray, D. Oesterhelt, R. Feick, H. Scheer and W. Zinth, Biochim. Biophys. Acta 1142, 99 (1993).

[5] C. Kirmaier and D. Holten, Proc. Natn. Acad. Sci. U.S.A. 87, 3552 (1990).

[6] M. H. Vos, J. C. Lambry, S. Robles, D. C. Youvan, J. Breton and J. C. Martin, Proc. Natn. Acad. Sci. U.S.A. 88, 8885 (1991).

[7] T. J. DiMagno, S. J. Rosenthal, X. Xie, M. Du, C.-K. Chan, D. Hanson, M. Schiffer, J. Norris and G. R. Fleming, The Photosynthetic Bacterial Reaction Center II (Edited by J. Breton and A. Verméglio). Plenum, New York (1992).

[8] H. J. M. de Groot, J. Raap, C. Winkel, A. J. Hoff and J. Lugtenburg, Chem. Phys. Lett. 169, 307 (1990).

[9] M. R. Fischer, H. J. M. de Groot, J. Raap, C. Winkel, A. J. Hoff and J. Lugtenburg, Biochemistry 31, 11038 (1992).

[10] S. Shochat, P. I. van Noort, R. van der Vos, S. C. M. Otte, H. Schelvis, J. Vrieze, F. A. M. Kleinherenbrink, P. Gast and A. J. Hoff, Proceedings of the IXth International Congress on Photosynthesis, Nagoya-shi, Japan (Edited by N. Murata), p. 413. Kluwer Academic (1992).

[11] S. Shochat, T. Arlt, C. Francke, P. Gast, P. I. van Noort, S. C. M. Otte, H. P. M. Schelvis, S. Schmidt, E. Vijgenboom, J. Vrieze, W. Zinth and A. J. Hoff, Photosyn. Res. 40, 55 (1994).

[12] P. I. van Noort, S. Shochat, S. Schmidt, T. Arlt, J. P. M. Schelvis, P. Gast, T. J. Aartsma, J. Amesz, W. Zinth and A. J. Hoff, Photosyn. Res., in press.

[13] C. Winkel, M. W. M. M. Aarts, F. R. van der Heide, E. G. Buitenhuis and J. Lugtenburg, Rec. Trav. Chim. 108, 139 (1989).

[14] J. Raap, C. Winkel, A. H. M. de Wit, A. H. H. van Houten, A. J. Hoff and J. Lugtenburg, Analyt. Biochem. 191, 9 (1990).

[15] H. J. M. de Groot, V. Copie, S. O. Smith, P. J. Allen, C. Winkel, J. Lugtenburg, J. Herzfeld and R. G. Griffin, J. Magn. Res. 77, 251 (1988).

[16] H. J. M. de Groot, S. O. Smith, A. C. Kolbert, J. M. L. Courtin, C. Winkel, J. Lugtenburg, J. Herzfeld and R. G. Griffin, J. Magn. Res. 91,30 (1991).

[17] P. J. Allen, F. Creuzet, H. J. M. de Groot and R. G. Griffin, J. Magn. Res. 92, 614 (1991).

[18] W. W. Parson, Z.-T. Chu and A. Warshel, Biochim. Biophys. Acta 1017, 251 (1990).

[19] U. Finkele, C. Lauterwasser, W. Zinth, K. A. Gray and D. Oesterhelt, Biochemistry 29, 8517 (1990).

[20] V. Nagarajan, W. W. Parson, D. Gaul and C. Schenck, Proc. Natn. Acad. Sci. U.S.A. 87, 7888 (1990)

[21] V. Nagarajan, D. Davis, W. Parson and C. Schenck, Biochemistry 32, 12324 (1993).

[22] C.-K. Chan, L. X.-Q. Chen, T. J. DiMagno, D. K. Hanson, S. L. Nance, M. Schiffer, J. R. Norris and G. R. Fleming, Chem. Phys. Lett. 176, 366 (1991).

[23] T. A. Mattioli, K. A. Gray, M. Lutz, D. Oesterhelt and B. Robert, Biochemistry 30, 1715 (1991).

[24] H. J. M. de Groot, S. O. Smith, J. M. L. Courtin, E. van den Berg, C. Winkel, J. Lugtenburg, R. G. Griffin and J. Herzfeld, Biochemistry 29, 6873 (1990).

[25] A. E. McDermott, L. K. Thompson, M. R. Farrar, S. Pelletier, J. Lugtenburg, J. Herzfeld and R. G. Griffin, Biochemistry 30, 8366 (1991).

SA(A) 51:1-J 
[26] S. V. Kolaczkowski, P. A. Lyle and G. J. Small, The Photosynthetic Bacterial Reaction Center II (Edited by J. Breton and A. Verméglio). Plenum, New York (1992).

[27] P. A. Lyle, S. V. Kolaczkowski and G. J. Small, J. Phys. Chem. 97, 6924 (1993).

[28] H. Strub, A. J. Beeler, D. M. Grant, J. Michl, P. W. Cutts and K. Zilm, J. Am. Chem. Soc. 105, 3333 (1983).

[29] K. W. Hart, D. J. Halsall and J. J. Holbrook, Biomolecular Spectroscopy (Edited by R. J. H. Clark and R. E. Hester), Part A, p. 195 (1993).

[30] J. Tang, Z. Wang and J. R. Norris, J. Chem. Phys. 99, 979 (1993).

[31] M. H. Vos, F. Rappaport, J. C. Lambry, J. Breton and J. L. Martin, Nature 363, 320 (1993).

[32] W. W. Parson, Chlorophylls (Edited by H. Scheer), p. 1169. CRC Press, Boca Raton, Florida (1990). 